\title{
Sensitivity Analysis for Durability of High Performance Concrete Containing Nano-particles based on Grey Relational Grade
}

\author{
Xiaohang Wei \\ China Road \& Bridge Corporation, Beijing 100011, China
}

Peng Zhang (Corresponding author)

College of Water Conservancy and Environment Engineering, Zhengzhou University

Zhengzhou 450001, China

Tel: 86-371-6388-8043 E-mail: zhangpeng8008@yahoo.com.cn

Received: March 31, 2011

Accepted: April 13, 2011

doi:10.5539/mas.v5n4p68

\begin{abstract}
There are many effect factors of mix proportion on anti-permeability and anti-freezing durability of high performance concrete containing nano-particles, such as the dosage of cement, nanomaterials, mineral fine admixture, chemical admixture and the value of water-binder ratio and sand ratio. The aim of this study was to evaluate the effect of these effect factors on durability of high performance concrete containing nano-particles and find out the main factors. Applying grey relational analysis method, the relational grades between the effect factors and diffusion coefficient of $\mathrm{Cl}^{-}$, and the relational grades between the effect factors and anti-freezing durability coefficient of high performance concrete containing nano-particles were calculated. Besides, the sequence results of influencing degree of the factors to affect the anti-permeability and freezing-thawing resistance were obtained. The results indicate that water-binder ratio, dosage of cement and dosage of nano- particles have the greatest influence on chloride permeability and freeze-thaw resistance of high performance concrete containing nano- particles among the 7 selected parameters of design of mix proportion. In order to improve anti-permeability of $\mathrm{Cl}^{-}$and freeze-thaw resistance of high performance concrete containing nano-particles, water-binder ratio, the dosage of cement and nano-materials must be controlled strictly. It had better decrease water-binder ratio and the dosage of cement, besides increase the dosage of nano-materials.
\end{abstract}

Keywords: Sensitivity analysis, Anti-permeability, Freeze-thaw resistance, Grey relational grade

\section{Introduction}

With the development of modern material science, concrete is developing in the direction of high strength, high performance, multifunction and intelligentization. Especially, high performance concrete has been widely used in high rise buildings, large span bridges, marine buildings, highways, and so on (Yang et al. 2007). The high performance of high performance concrete includes higher strength, better workability, better volume stability and higher durability. There are mainly two technical measures to obtain the high performance of high performance concrete, which are using new type high efficiency water reducing agent and mixing mineral admixture into concrete. The former measure can reduce the water-binder ratio, increase the slump constant, and control the slump loss of concrete. So the concrete can achieve high density and excellent workability. As for the latter measure, the mineral admixture can fill the void inside the binder, participate in the hydration reaction of the binder, increase the density of concrete and improve the interface microstructure of concrete, so the durability and strength of concrete are improved (Yan 2008).

The nanomaterial is composed of particles with the particle diameter of 1-100 nm, which is a kind of micro-size material in the interfacial transition zone between the clusters and macro-matter. With the specific nanoeffects, as a new material, the nanomaterial has displayed wide application prospect in many fields, and the nanomaterial is dubbed as the most promising material of the 21st century (Fu 2004). In recent years, with the deepening of research of nanomaterials and the reduction of manufacturing cost of nanomaterials, the application fields of nanomaterials become more and more, and many researchers have carried out a large amount of research work on nanomaterials. Colston (2000) and Li (2004) studied the microstructure of high performance concrete containing nano-particles. The result indicates that nanomaterials can distinctly improve the structural behavior of the cement paste of high performance concrete and the structural behavior of the interface between the cement paste and the aggregate. Jo et al. (2008) and Li (2007) experimentally investigated the effect of nano-particles on mechanical properties of high performance concrete. The results indicate that the compressive strength of early stage, tensile strength, flexural tensile strength and the fatigue life of high performance can be increased with the mixing of nano-particles, and besides, the addition of nano-particles has vibration attenuation effect on concrete structures. Ji (2005), Zhang (2010) and Qian et al. (2009) experimentally investigated the effect of nano-particles on durability of high performance concrete, and the results indicate that nano-particles can obviously improve 
the durability of high performance concrete.

Anti-permeability and freezing-thawing resistance are the most important two aspects of durability of high performance concrete. For high performance concrete containing nano-particles, there are a lot of factors influencing the two kinds of durability, such as the dosage of cement, nanomaterials, mineral fine admixture, chemical admixture and the value of water-binder ratio and sand ratio. However, none of the other phases have studied the influence degree of these factors on high performance concrete containing nano-particles. The general methods based on classical statistics were not efficient enough to find out the main factors. Grey theory method had a great tendency to provide useful approach deal with the problems of limited and superficial ruleless data processing, so as to find the characteristic of system itself (Deng 1989). Grey relational analysis is based on geometrical mathematics, which is compliance with the principles of normality, symmetry, entirety, and proximity. Therefore, applying the method of grey relational analysis, we conducted this study to analyze the correlation between the durability (anti-permeability and freezing-thawing resistance, respectively) of high performance concrete containing nano- $\mathrm{SiO}_{2}$ and the relevant influencing factors of anti-permeability and freezing-thawing resistance. And then, the rank ordering of the grey relational grades of the relevant influencing factors can be obtained, which can improve the further application of nano- $\mathrm{SiO}_{2}$ in high performance concrete.

\section{Evaluation index of durability of high performance concrete}

\subsection{Evaluation Index of Anti-permeability}

There are many evaluation methods of anti-permeability for normal concrete. However, the permeability of high performance concrete is usually much lower than that of normal concrete, and it is very difficult to measure the actual permeability in some traditional standard test methods. Furthermore, for the durability of concrete, the permeability of water is one important aspect to be considered, besides, it must be considered that the permeation of $\mathrm{Cl}^{-}$can cause the destruction of the reinforcement inside the concrete permeability. Therefore, we adopt the permeability of $\mathrm{Cl}^{-}$to evaluate the anti-permeability of high performance concrete in this study, and the permeability of $\mathrm{Cl}^{-}$can be expressed as the diffusion coefficient of $\mathrm{Cl}^{-}$. For high performance concrete, there is a linear correlation relationship between the diffusion coefficient of $\mathrm{Cl}^{-}$and the electric quantity through the specimen within $6 \mathrm{~h}$, and this relationship can be expressed as follows (Feng and Xing 2001):

$$
D=2.71153+0.00421 Q
$$

where, $D$, diffusion coefficient of $\mathrm{Cl}^{-}$of high performance concrete, $\mathrm{cm}^{2} / \mathrm{s} ; Q$, electric quantity through the specimen within $6 \mathrm{~h}, \mathrm{C}$. The smaller diffusion coefficient of $\mathrm{Cl}^{-}$of high performance concrete indicates that the permeability of $\mathrm{Cl}^{-}$is lower and the concrete has better anti-permeability. On the contrary, high performance concrete has worse anti-permeability with larger diffusion coefficient of $\mathrm{Cl}^{-}$. The electric quantity through the specimen can be measured referring to the standard of ASTM.

\subsection{Evaluation Index of Freezing-thawing Resistance}

Freezing-thawing cycle is another significant influencing factor on durability of concrete. As a result, in the study of durability of concrete, freezing-thawing resistance of concrete is an important research content, which has extensive practical significance on the application of high performance concrete (Mather 2004). Anti-freezing durability of concrete has the significant effect on the service life and service quality of concrete structures, and besides, the area coverage of the freezing injury of concrete is quite wide. Anti-freezing durability of high performance concrete containing nano-particles can be measured according to the standard of ASTM. Anti-freezing durability coefficient can be calculated as follows:

$$
D F=\frac{P \times N}{300}
$$

where, $D F$, anti-freezing durability coefficient of high performance concrete, $\% ; N$, the number of freezing-thawing cycle; $P$, relative dynamic elastic modulus of concrete after $N$ times of freezing-thawing cycle, \%. The larger anti-freezing durability coefficient of high performance concrete indicates that high performance concrete has better freezing-thawing resistance. On the contrary, high performance concrete has worse freezing-thawing resistance with smaller anti-freezing durability coefficient.

\section{Method of grey relational analysis}

\subsection{Principles of grey relational analysis}

Grey relational analysis is the important content of grey system theory and it determines the otherness and proximity between the reference sequence and the compare sequences through the curves formed by the reference sequence and the compare sequences. If the geometry shape of the curve of one compare sequence is more similar with that of the reference sequence, it indicates that this compare sequence has more similar variation tendency with that of the reference sequence, and its relational grade is larger (Deng 1989). Relational grade shows how close the compared factor is to the reference factor. The most significant influencing factor to 
the reference factor of the system, which has the largest relevance with the reference factor, can be found by calculating the relational grade.

\subsection{Data pre-processing}

The essence of grey relational analysis lies in the survey of the correlative degrees of some comparable sequences of data on the preferred reference sequence by means of a straightforward and simple model, from which the preferential ranking influencing the target, i.e., reference sequence, can then be made (Deng 1989). Suppose the reference and comparable sequences are respectively denoted as $x_{0}^{(0)}(k)$ and $x_{i}^{(0)}(k)$, where $i=1,2, \ldots, m$, and $k=1,2, \ldots, n$.

However, the raw data sequence may every so often differ from the others in terms of the range and unit, as a result, it brings about the incomparable condition during grey relational analysis. Based on the above reason, ahead of implementing the present analysis, data pre-processing of transferring the original sequence to a comparable one is required. In this study, the raw data were transformed into dimensionless forms by initial-value pre-processing. Then, the original sequence can be normalized as:

$$
\begin{aligned}
& x_{0}^{*}(k)=\frac{x_{0}^{(0)}(k)}{x_{0}^{(0)}(1)} \\
& x_{i}^{*}(k)=\frac{x_{i}^{(0)}(k)}{x_{i}^{(0)}(1)}
\end{aligned}
$$

where, $x_{0}^{*}(k)$ and $x_{i}^{*}(k)$ are the sequences after data pre-processing, and $i=1,2, \ldots, m$, and $k=1,2, \ldots, n$.

3.3 Calculation of grey relational coefficient

After the establishment of data pre-processing as stated in the last subsection, the grey relational coefficient can be calculated, which is defined as:

$$
\xi_{i}(k)=\frac{\Delta_{\min }+\rho \Delta_{\max }}{\Delta_{0 i}(k)+\rho \Delta_{\max }}
$$

where $i=1,2, \ldots, m, \Delta_{0 i}(k)$ and the deviation sequences $\Delta_{\min }$ and $\Delta_{\max }$ can be defined as:

$$
\begin{gathered}
\Delta_{0 i}(k)=\left|x_{0}^{*}(k)-x_{i}^{*}(k)\right| \\
\Delta_{\min }=\min _{i} \min _{k}\left|x_{0}^{*}(k)-x_{i}^{*}(k)\right| \\
\Delta_{\max }=\max _{i} \max _{k}\left|x_{0}^{*}(k)-x_{i}^{*}(k)\right|
\end{gathered}
$$

where $\rho$ is the distinguishing coefficient to adjust the range of the comparison environment, $\rho \in[0,1]$, the value of which is selected to be 0.5 in most situations, and $i=1,2, \ldots, m$, and $k=1,2, \ldots, n$.

3.4 Calculation of grey relational grade

As there are too many relational coefficients to be compared directly, further data reduction makes use of average-value processing to convert each sequence into its mean. The mean also is known as the relational grade, which can be derived as follow:

$$
\gamma_{i}=\frac{1}{n} \sum_{k=1}^{n} \xi_{i}(k)
$$

where $\gamma_{i}$ is the grey relational grade, and $i=1,2, \ldots, m$, and $k=1,2, \ldots, n$. The grey relational grade stands for the level of correlation between the target sequence and the comparable sequence (Deng 1989). If the two sequences are identically coincidence, then the value of grey relational grade is equal to 1 . It also indicates the degree of influence on the target sequence exerted by the comparable sequence. Therefore, if a particular comparable sequence is more important than the other comparable sequences to the reference sequence, then the grey relational grade for that comparable sequence and reference sequence will be higher than other grey relational grades.

\section{Grey relational analysis of durability effect factors}

With the electric quantity measured, the diffusion coefficient of $\mathrm{Cl}^{-}$can be calculated by Eq. (1). With the measured values, the anti-freezing durability coefficient can be calculated by Eq. (2). The mix proportions of high performance concrete containing nano-SiO ${ }_{2}$ and the experiment results of diffusion coefficient of $\mathrm{Cl}^{-}$and anti-freezing durability coefficient are given in Table 1 (Guo 2006). The curing period of the specimens is $28 \mathrm{~d}$. 


\subsection{Grey relational analysis of effect factors on anti-permeability}

The values of diffusion coefficient of $\mathrm{Cl}^{-}$were chosen as the reference sequence to found the grey relational analysis model of anti-permeability of high performance concrete containing nano- $\mathrm{SiO}_{2}$. In this grey relational analysis model, water-binder ratio, dosage of cement, dosage of nano- $\mathrm{SiO}_{2}$, dosage of fly ash, dosage of silica fume, dosage of superplasticizer and sand ratio were taken as the effect factors of mix proportion on anti-permeability durability of high performance concrete containing nano- $\mathrm{SiO}_{2}$. And the values of these mix proportion parameters of 6 mix proportions were taken as 6 compare sequences. All the reference sequence and compare sequences after data pre-processing using Eq. (3) and (4) can be substituted into Eq. (6), (7) and (9), and the grey relational coefficient can be calculated by Eq. (5). The distinguishing coefficient $\rho$ was selected as 0.5 in this study. Finally, the following grey relational grades can be obtained with the grey relational coefficient substituted into Eq. (9):

$\gamma_{1}=0.965$ (Grey relational grade of water-binder ratio and diffusion coefficient of $\mathrm{Cl}^{-}$);

$\gamma_{2}=0.937$ (Grey relational grade of dosage of cement and diffusion coefficient of $\mathrm{Cl}^{-}$);

$\gamma_{3}=0.875$ (Grey relational grade of dosage of nano- $\mathrm{SiO}_{2}$ and diffusion coefficient of $\mathrm{Cl}^{-}$);

$\gamma_{4}=0.708$ (Grey relational grade of dosage of silica fume and diffusion coefficient of $\mathrm{Cl}^{-}$);

$\gamma_{5}=0.781$ (Grey relational grade of dosage of fly ash and diffusion coefficient of $\mathrm{Cl}^{-}$);

$\gamma_{6}=0.785$ (Grey relational grade of sand ratio and diffusion coefficient of $\mathrm{Cl}^{-}$);

$\gamma_{7}=0.530$ (Grey relational grade of dosage of superplasticizer and diffusion coefficient of $\mathrm{Cl}^{-}$).

The corresponding relational grade sequence is: $\gamma_{1}>\gamma_{2}>\gamma_{3}>\gamma_{6}>\gamma_{5}>\gamma_{4}>\gamma_{7}$, which is the sequence of the correlative extent of the effect factors on anti-permeability of high performance concrete containing nano- $\mathrm{SiO}_{2}$. From the principle of grey relational analysis, it is known that a relational grade close to 1 means the correlative extent of the factor to anti-permeability is great (Shen and Du 2005). Calculating results showed that all factors have influence on anti-permeability of high performance concrete containing nano- $\mathrm{SiO}_{2}$. There was more noticeable influence by water-binder ratio, dosage of cement and dosage of nano- $\mathrm{SiO}_{2}$ on anti-permeability of high performance concrete containing nano- $\mathrm{SiO}_{2}$.

\subsection{Grey relational analysis of effect factors on freezing-thawing resistance}

The values of anti-freezing durability coefficient were chosen as the reference sequence to found the grey relational analysis model of freezing-thawing resistance of high performance concrete containing nano- $\mathrm{SiO}_{2}$. In this grey relational analysis model, the effect factors of mix proportion on freezing-thawing resistance of high performance concrete containing nano- $\mathrm{SiO}_{2}$ and the compare sequences were the same as those of the grey relational analysis model of anti-permeability. The data pre-processing of all the sequences, the calculation of grey relational coefficient and the calculation of grey relational grade is the same with that of the grey relational analysis of effect factors on anti-permeability of high performance concrete containing nano- $\mathrm{SiO}_{2}$. And then the following grey relational grades can be obtained as:

$\gamma_{1}=0.929$ (Grey relational grade of water-binder ratio and anti-freezing durability coefficient);

$\gamma_{2}=0.958$ (Grey relational grade of dosage of cement and anti-freezing durability coefficient);

$\gamma_{3}=0.857$ (Grey relational grade of dosage of nano- $\mathrm{SiO}_{2}$ and anti-freezing durability coefficient);

$\gamma_{4}=0.615$ (Grey relational grade of dosage of silica fume and anti-freezing durability coefficient);

$\gamma_{5}=0.575$ (Grey relational grade of dosage of fly ash and anti-freezing durability coefficient);

$\gamma_{6}=0.695$ (Grey relational grade of sand ratio and anti-freezing durability coefficient);

$\gamma_{7}=0.503$ (Grey relational grade of dosage of superplasticizer and anti-freezing durability coefficient).

The corresponding relational grade sequence is: $\gamma_{2}>\gamma_{1}>\gamma_{3}>\gamma_{6}>\gamma_{4}>\gamma_{5}>\gamma_{7}$, which is the sequence of the correlative extent of the effect factors on freezing-thawing resistance of high performance concrete containing nano- $\mathrm{SiO}_{2}$. From the principle of grey relational analysis, it is known that a relational grade close to 1 means the correlative extent of the factor to anti-permeability is great. Calculating results showed that all factors have influence on freezing-thawing resistance of high performance concrete containing nano- $\mathrm{SiO}_{2}$. There was more noticeable influence by water-binder ratio, dosage of cement and dosage of nano- $\mathrm{SiO}_{2}$ on freezing-thawing resistance of high performance concrete containing nano- $\mathrm{SiO}_{2}$.

\section{Conclusions}

Applying grey relational analysis method, this paper calculated the relational grades between the 
effect factors of mix proportion and diffusion coefficient of $\mathrm{Cl}^{-}$, and the relational grades between the effect factors of mix proportion and anti-freezing durability coefficient of high performance concrete containing nano$\mathrm{SiO}_{2}$. Besides, the sequence results of influencing degree of the factors to affect the anti-permeability and freezing-thawing resistance were obtained. The following conclusions can be draw from the analysis results presented in this paper:

1. The durability of high performance concrete containing nano- $\mathrm{SiO}_{2}$ is affected by various kinds of factors, and various factors have different sensitivity. Grey relational analysis could be well used to analyze the sensitivity of the effect factors on anti-permeability and freezing-thawing resistance of high performance concrete containing nano- $\mathrm{SiO}_{2}$. Applying this analysis method, the analysis results can be quantified, and the primary and secondary relationship of the effect factors can be clearly determined, which has great guiding significance on the design of mix proportion and construction of high performance concrete containing nano$\mathrm{SiO}_{2}$.

2. For the 7 selected parameters of design of mix proportion, the importance of they affecting anti-permeability of high performance concrete containing nano- $\mathrm{SiO}_{2}$ has following sequence: water-binder ratio $>$ dosage of cement $>$ dosage of nanomaterials $>$ sand ratio $>$ dosage of fly ash $>$ dosage of silica fume $>$ dosage of chemical admixture, and the importance of they affecting freezing-thawing resistance has following sequence: dosage of cement $>$ water-binder ratio $>$ dosage of nanomaterials $>$ sand ratio $>$ dosage of silica fume $>$ dosage of fly ash $>$ dosage of chemical admixture.

3. Among the 7 selected parameters of design of mix proportion, water-binder ratio, dosage of cement and dosage of nano- $\mathrm{SiO}_{2}$ have the greatest influence on anti-permeability and freezing-thawing resistance of high performance concrete containing nano- $\mathrm{SiO}_{2}$. Therefore, in order to improve durability of high performance concrete containing nano-particles, water-binder ratio, the dosage of cement and nanomaterials must be controlled strictly.

\section{References}

Colston, S. L., O'Connor, D., Barnes, P., Mayes, E. L., Mann, S., Freimuth, H. and Ehrfeld, W. (2000). The incorporation of zeolites and inorganic nano-particles into cement micro-structures. Journal of Materials Science Letters, 19(12), 1085-1088.

Deng, J. L. (1989). Introduction to grey system theory. The Journal of Grey System, 1(1), 1-24.

Feng, N. Q. and Xing, F. (2001). Chlorine ion permeability and electrical conductance of high performance concrete. Concrete, 23(11), 3-7.

Fu, M. F., Xiong, J. G. and Song, G. Q. (2004). Study and application of nano-materials in concrete. Engineering Mechanics, 21(S1), 48-51.

Guo, B. L. (2006). Laboratory study on the properties of high performance concrete with nano- $\mathrm{SiO}_{2}$. MSc (Eng). thesis, Dalian University of Technology, Dalian, China.

Ji, T. (2005). Preliminary study on the water permeability and microstructure of concrete incorporating nano-SiO2. Cement and Concrete Research, 35(10), 1943-1947.

Jo, B. W., Park, S. K. and Kim, D. K. (2008). Mechanical properties of nano-MMT reinforced polymer composite and polymer concrete. Construction and Building Materials, 22(1), 14-20.

Li, G. Y. (2004). Properties of high-volume fly ash concrete incorporating nano-SiO2. Cement and Concrete Research, 34(6), 1043-1049.

Li, H., Zhang, M. H. and Ou, J. P. (2007). Flexural fatigue performance of concrete containing nano-particles for pavement. International Journal of Fatigue, 29(7), 1292-1301.

Mather, B. (2004). Concrete durability. Cement and Concrete Composites, 26(1), 3-4.

Qian, K. L., Meng, T., Qian, X. and Zhan, S. L. (2009). Research on some properties of fly ash concrete with nano-CaCO3 middle slurry. Key Engineering Materials, 406-405, 189-190.

Shen, D. H. and Du, J. C. (2005). Application of gray relational analysis to evaluate HMA with reclaimed building materials. Journal of Materials in Civil Engineering, 17(4), 400-406.

Yan, H. J. (2008). Influence of composite nano-material on performance of concrete and cement mortar. New Building Materials, 35(7), 32-35.

Yang, R. H., Lu, W. X., Yu, S. H. and Li, K. (2007). Performance influence of composite nano-materials on concrete and cement mortar. Journal of Chongqing Jianzhu University, 29(5), 144-148.

Zhang, M. H. and Li, H. (2010). Pore structure and chloride permeability of concrete containing nano-particles for pavement. Construction and Building Materials, doi: 10.1016/j.conbuildmat.2010.07.032. 
Table 1. Mix Proportions and Experiment Results

\begin{tabular}{|c|c|c|c|c|c|c|c|c|c|c|c|c|}
\hline $\begin{array}{l}\text { Mixture } \\
\text { Number }\end{array}$ & $\begin{array}{l}W / B \\
(\%)\end{array}$ & $\begin{array}{c}W \\
\left(\mathrm{Kg} / \mathrm{m}^{3}\right)\end{array}$ & $\begin{array}{c}C \\
\left(\mathrm{Kg} / \mathrm{m}^{3}\right)\end{array}$ & $\begin{array}{c}N S \\
\left(\mathrm{Kg} / \mathrm{m}^{3}\right)\end{array}$ & $\begin{array}{c}S F \\
\left(\mathrm{Kg} / \mathrm{m}^{3}\right)\end{array}$ & $\begin{array}{c}F A \\
\left(\mathrm{Kg} / \mathrm{m}^{3}\right)\end{array}$ & $\begin{array}{c}S \\
\left(\mathrm{Kg} / \mathrm{m}^{3}\right)\end{array}$ & $\begin{array}{c}G \\
\left(\mathrm{Kg} / \mathrm{m}^{3}\right)\end{array}$ & $\begin{array}{l}S R \\
(\%)\end{array}$ & $\begin{array}{l}S P \\
(\%)\end{array}$ & $\begin{array}{c}D \\
\left(10^{-9} \mathrm{~cm}^{2} / \mathrm{s}\right)\end{array}$ & $\begin{array}{l}D F \\
(\%)\end{array}$ \\
\hline NHPC1 & 0.25 & 130 & 416 & 15.6 & 36.4 & 52 & 718 & 1172 & 38 & 3.0 & 4.1316 & 98.1 \\
\hline NHPC2 & 0.25 & 130 & 416 & 26 & 26 & 52 & 700 & 1190 & 37 & 3.3 & 4.1058 & 98.6 \\
\hline NHPC3 & 0.29 & 150 & 413.6 & 15.51 & 36.19 & 51.7 & 718 & 1172 & 38 & 1.8 & 4.5949 & 96.7 \\
\hline NHPC4 & 0.29 & 150 & 413.6 & 25.85 & 25.85 & 51.7 & 700 & 1190 & 37 & 2.1 & 4.5619 & 97.9 \\
\hline NHPC5 & 0.34 & 175 & 412 & 15.45 & 36.05 & 51.5 & 718 & 1172 & 38 & 1.4 & 5.6040 & 94.6 \\
\hline NHPC6 & 0.34 & 175 & 412 & 25.75 & 25.75 & 51.5 & 700 & 1190 & 37 & 1.8 & 5.2810 & 95.2 \\
\hline
\end{tabular}

Note: $W / B=$ Water-binder ratio; $W=$ Water; $C=$ Cement; $N S=$ Nano- $\mathrm{SiO}_{2} ; S F=$ Silica fume; $S P=$ Superplasticizer; $F A=$ Fly ash; $S=$ Sand; $G=$ Gravel; $S R=$ Sand ratio; $D=$ Diffusion coefficient of $\mathrm{Cl}^{-} ; D F=$ Anti-freezing durability coefficient. 